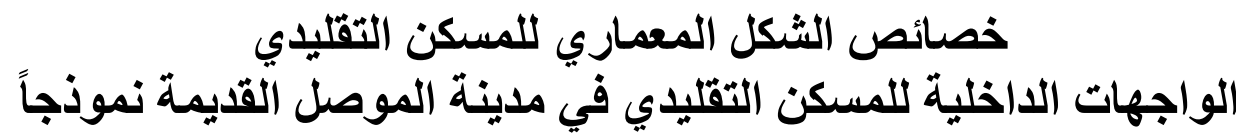

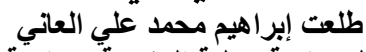

$$
\begin{aligned}
& \text { الهندسة المعمارية / كلية الهندسة / جامعة الموصل } \\
& \text { Mobil : } 009647701607447 \quad \text { E-mail : Talaat_aane@yahoo.com } \\
& \text { الخلاصة : }
\end{aligned}
$$

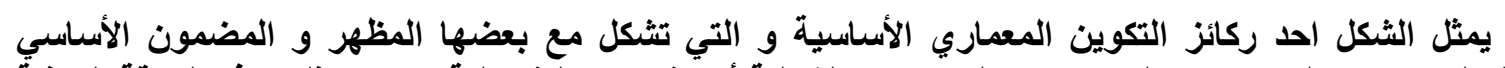

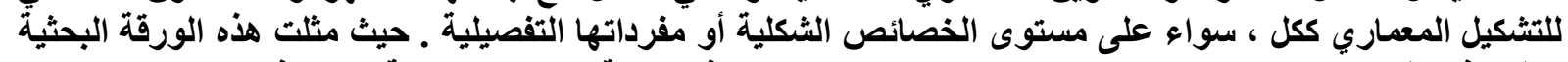

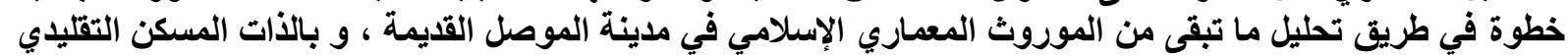

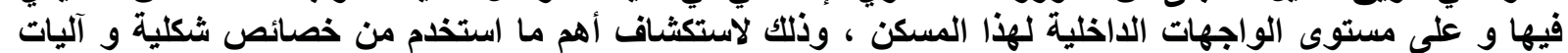

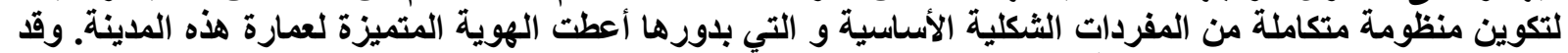

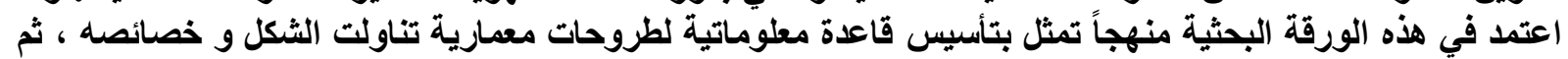

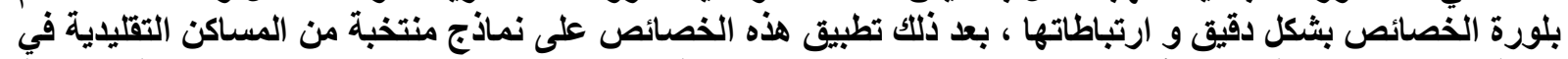

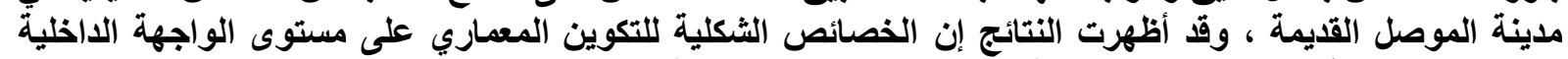

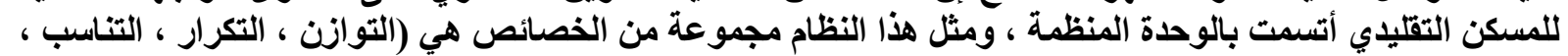

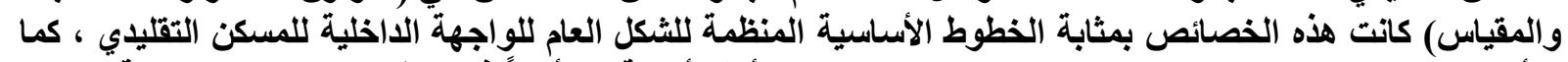

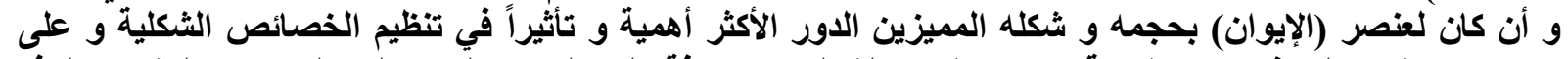

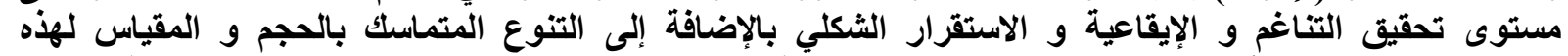

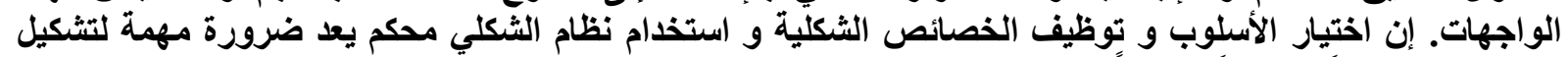

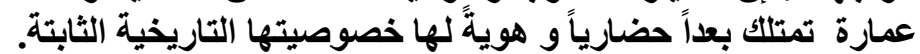

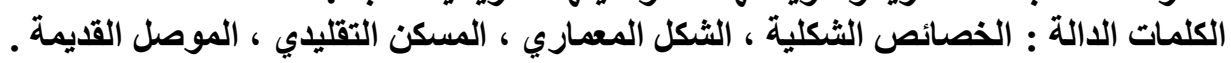

\title{
The Attributes of Architectural Form of Traditional House Internal Facades of Mosul's Traditional House as a Case-study
}

Talaat I. M. Alaane

Engineering Col. - Architecture Dept. - University of Mosul Mobil : $009647701607447 \quad$ E-mail : Talaat_aane@yahoo.com

\begin{abstract}
The form represents one of the major components of the architectural composition, which all constitute the architectural work, both partially or as a whole. This paper tries to analyze some remains of the Islamic architectural heritage in old Mosul concentrating on traditional houses and their facades in particular in order to investigate the rules and mechanisms which produce an integrated system of attributes that gave Mosul its own architectural identity. This paper adopts a methodology represented by establishing a data-base from multi architectural essays which deal with from, then applying concluded from them on selected examples of traditional houses in Mosul. Findings show that formal features on façade level were characterized by organized unity with concepts like balance, repetition, proportion, and scale. Such concepts were basic guide-lines in organizing the internal façade. The (Iwan) was the most important element due to its size and form which affect in shaping these facades. This is so important in achieving a local architecture with distinctive identity.
\end{abstract} Key words: Formal attributes, architectural form, traditional house, old Mosul. 


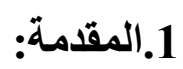

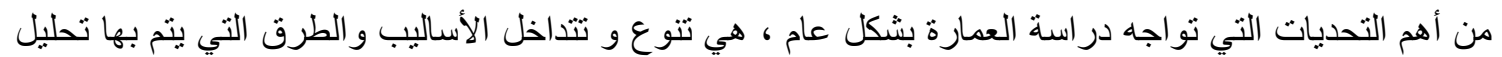

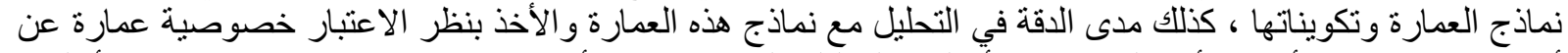

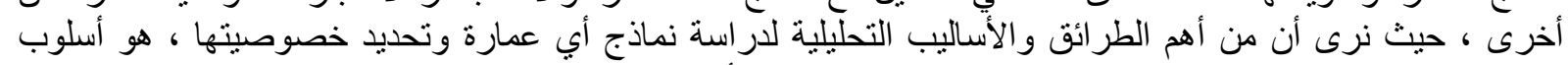

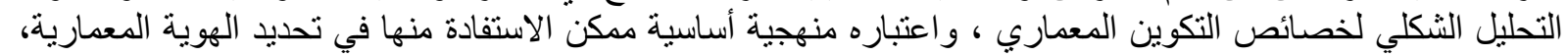

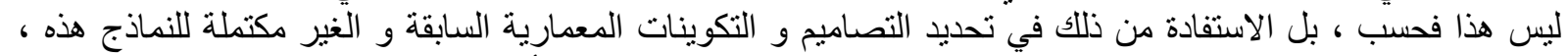

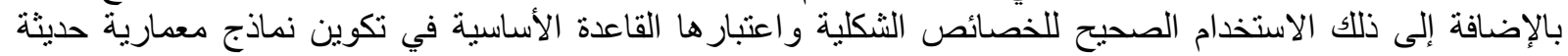

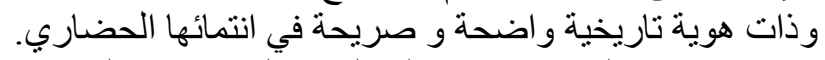

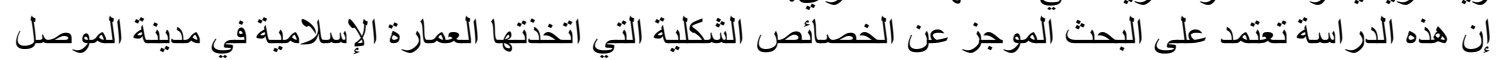

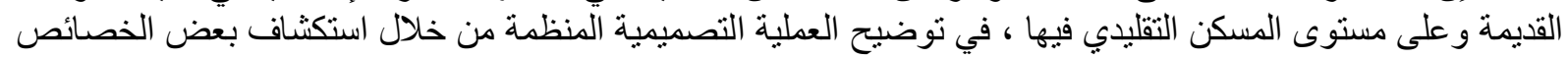

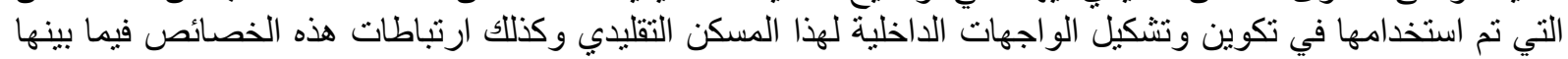

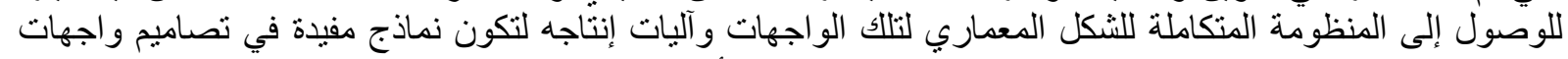

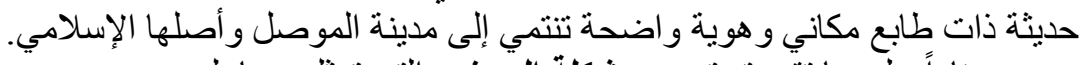

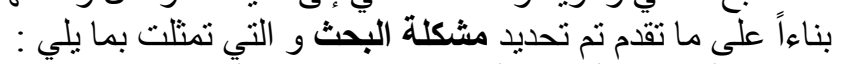

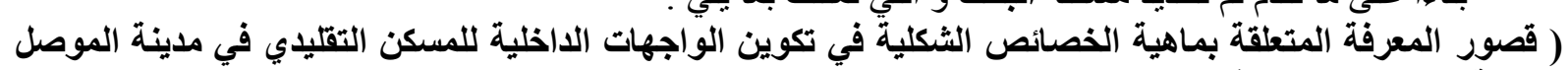

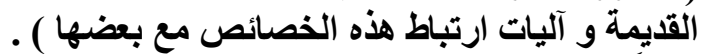

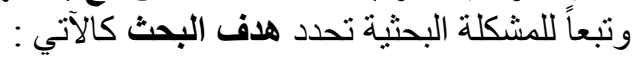

( الكثف و تحديد الخصائص الثكلية في تكوين الواجهات الداخلية للمسكن التقليدي في مدينة الموصل القديمة وتوضيح

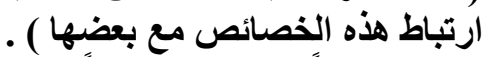

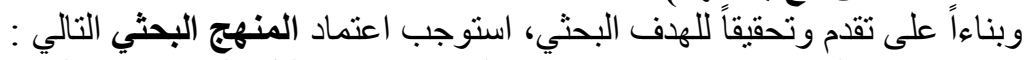

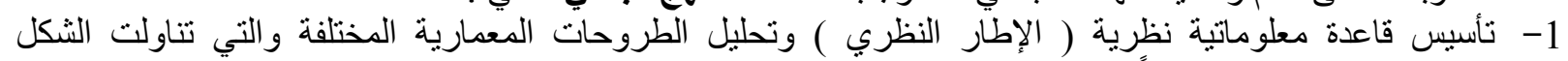

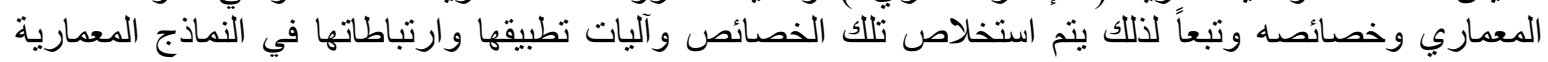

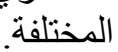

2- بلورة الإطار الخاص بالخصائص الثكلية والتي تتضمن تحديد تلك الخصائص ودراسة تحققها وارتباطها بعضها

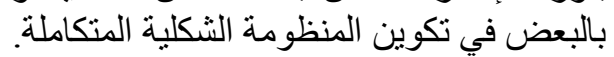

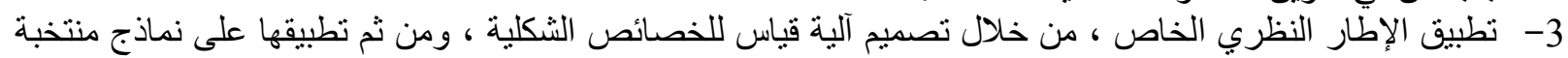

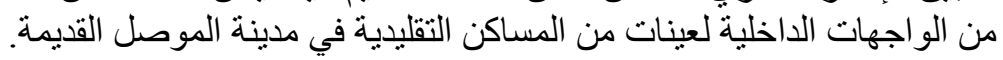

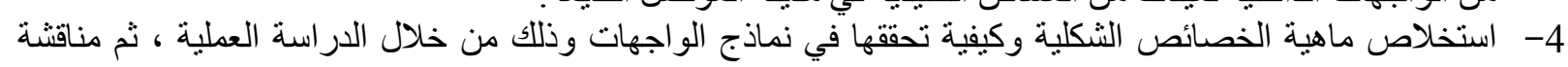
النتائج وطر ح الاستنتاجات و التوصيات.

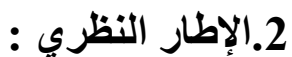

يوضح (Graves) كلا من عناصر الفنون المرئية ، وتعريفها ، و أنو اعها وتصنيفاتها ، و المبادئ التي يقوم عليها

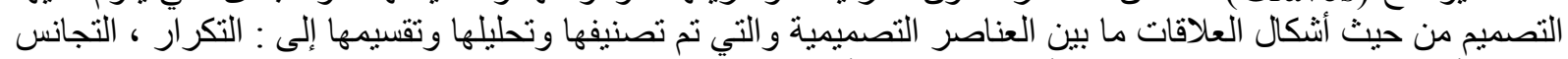

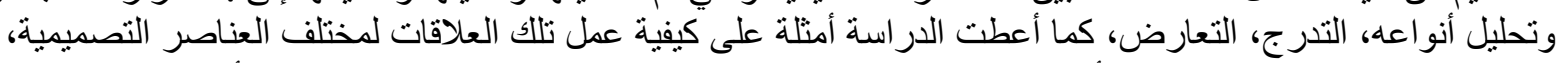

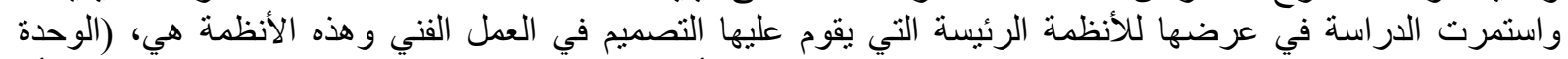

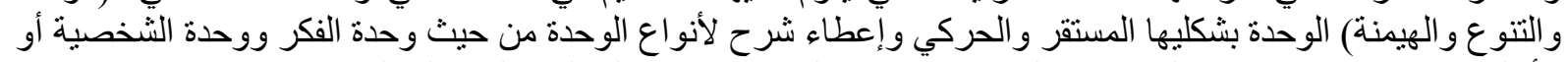

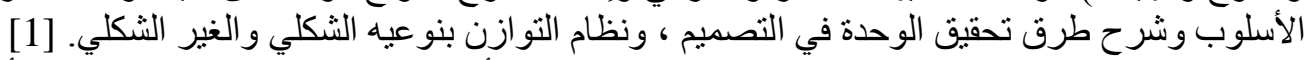

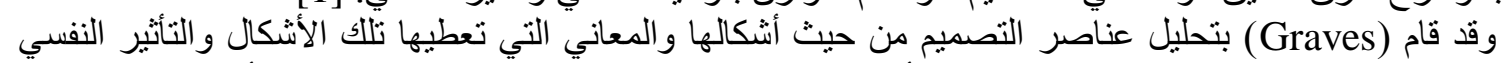

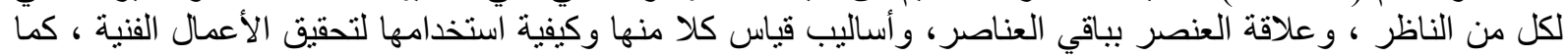

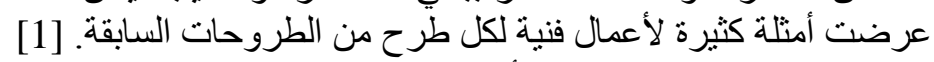

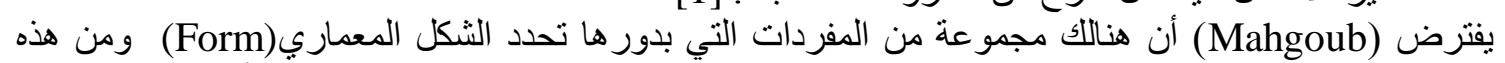

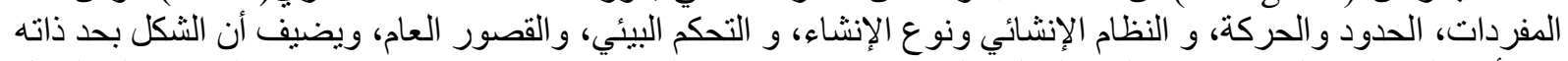

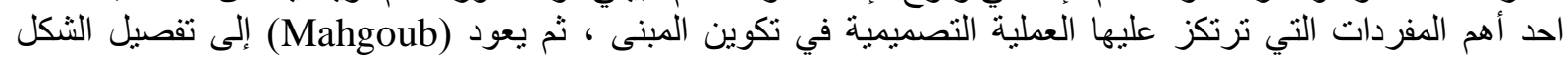

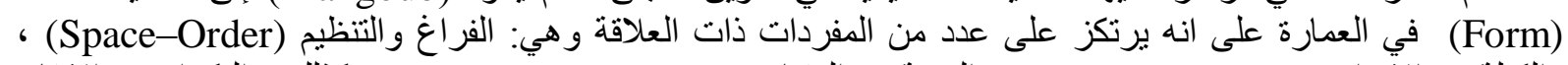

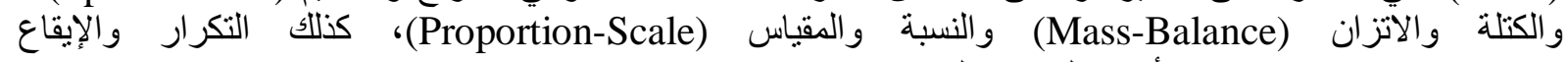

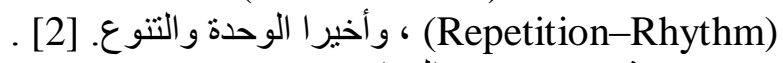
ويشير (Ching) إلى انه : 
(من الثيء المهم للشخص أن يفهم الحروف قبل أن يتعلم تكوين الكلمات وان يفهم أسس وقو اعد التركيب قبل كتابة الجمل،

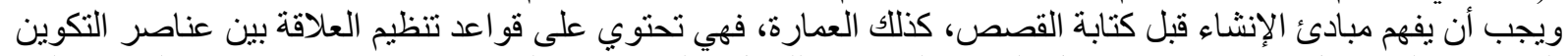

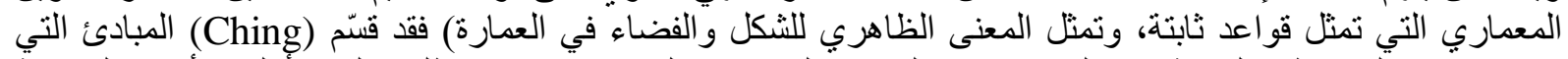

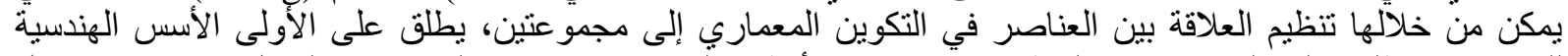

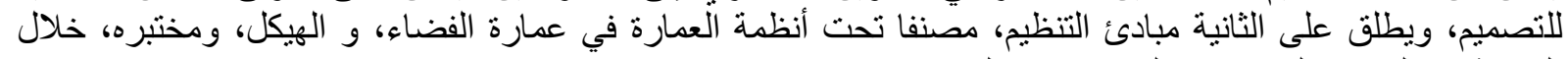

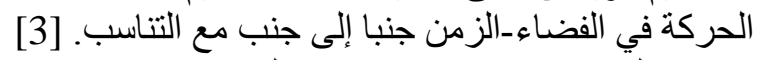

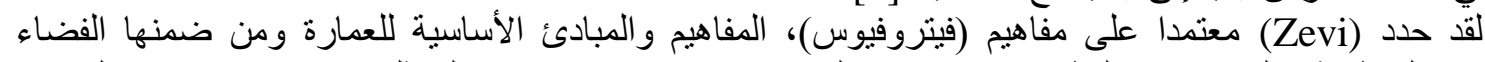
(Space) Proportion

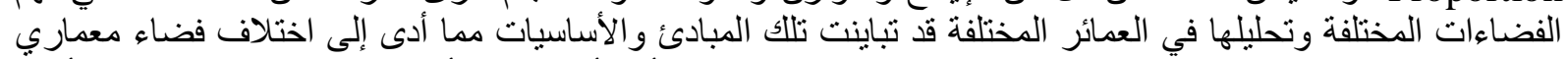

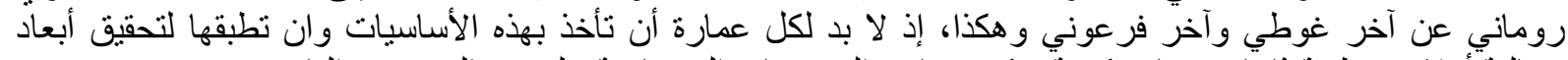

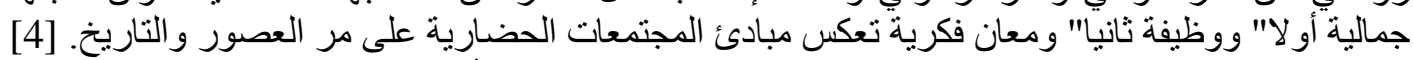

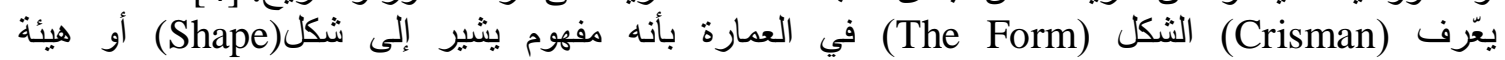
(Configuration)

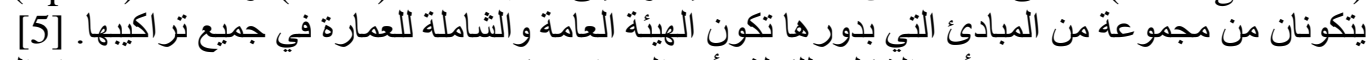

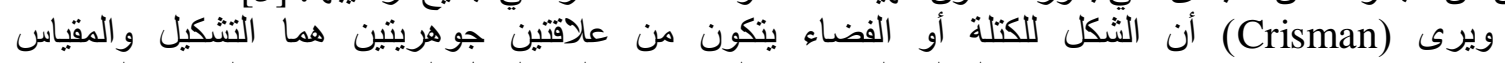

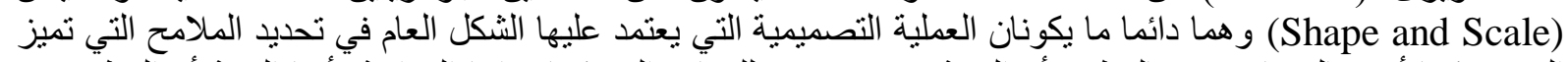

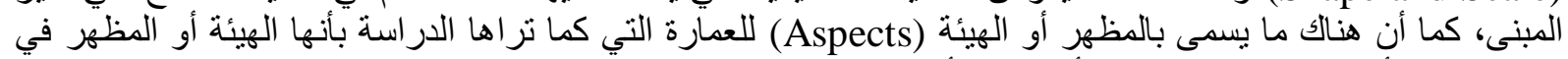

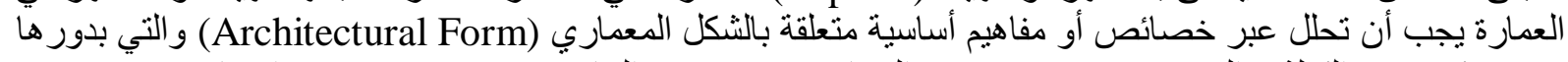

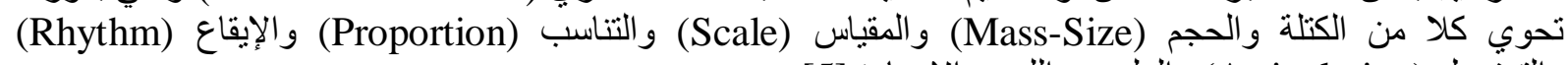

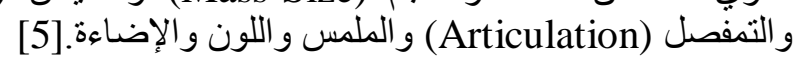

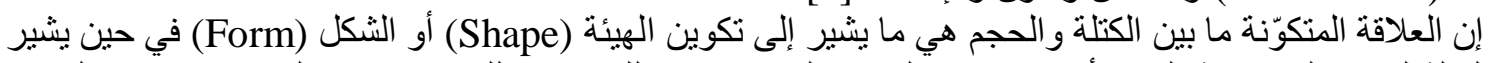

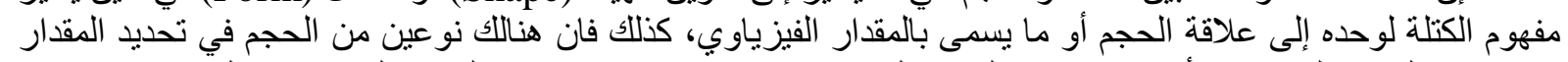

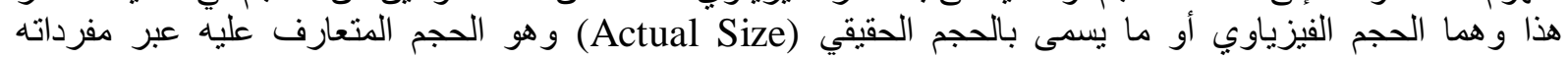

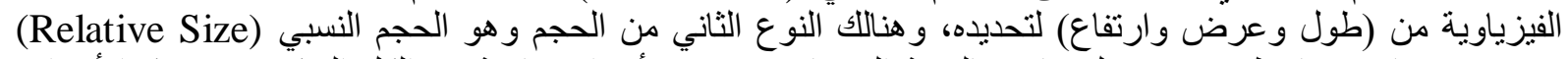

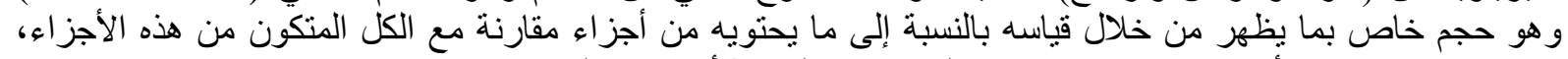

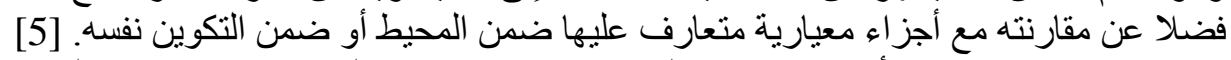

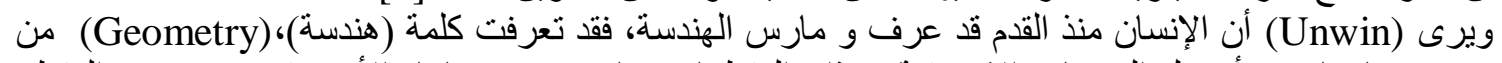

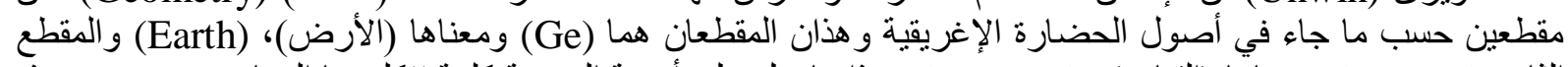

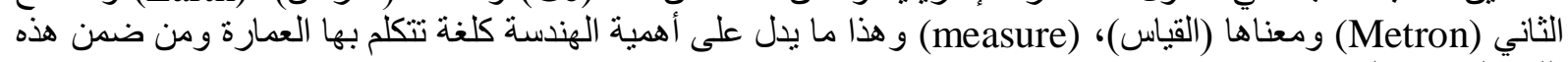

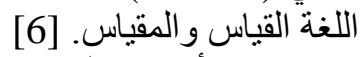

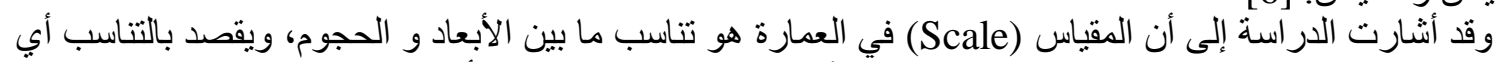

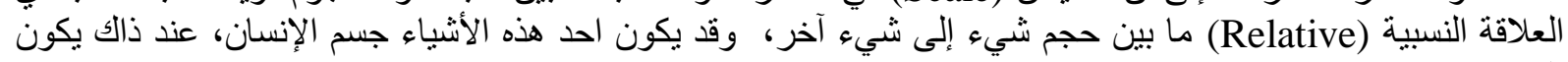

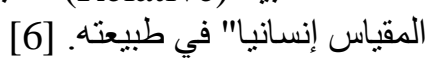

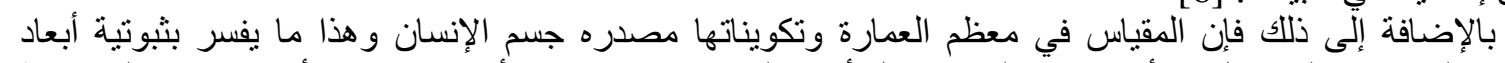

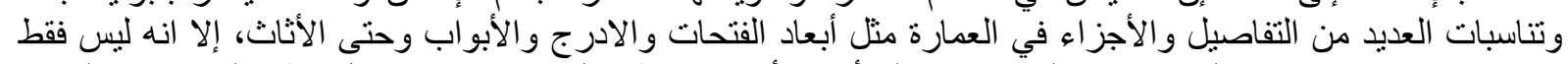

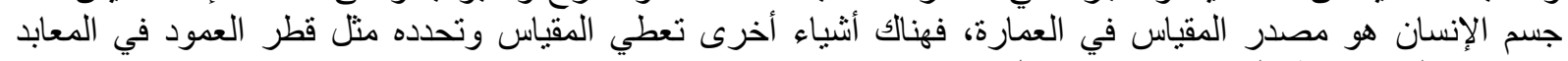

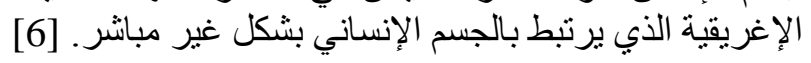

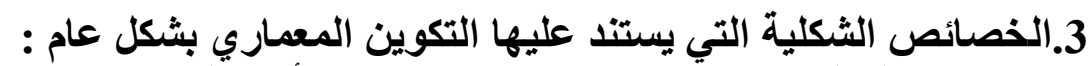

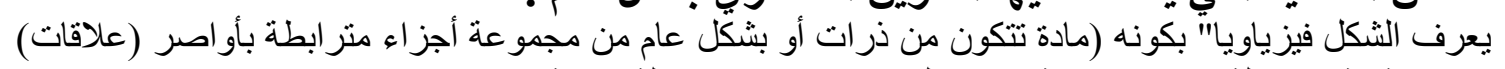

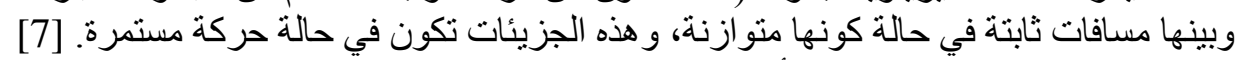

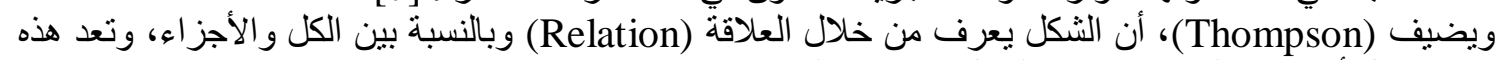
النسبة ثابتة في كل أنواع، إذ لو لاها لا يقوم الثنكل إلا بتغير المادة.

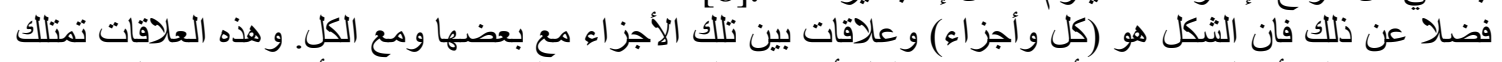

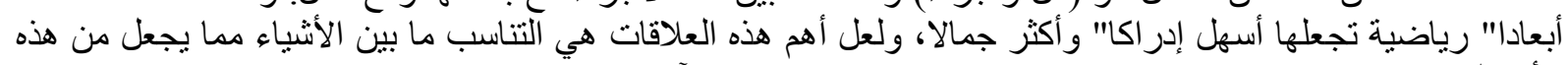

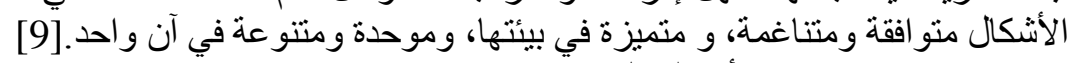

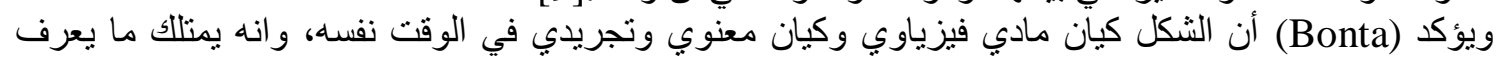




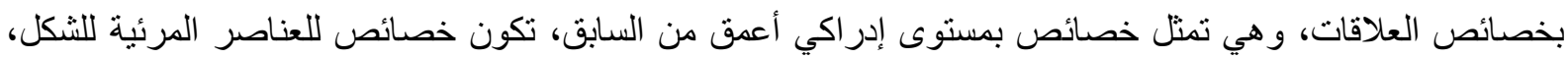

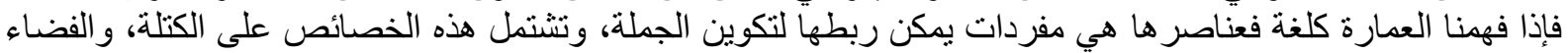

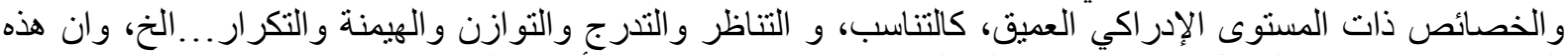

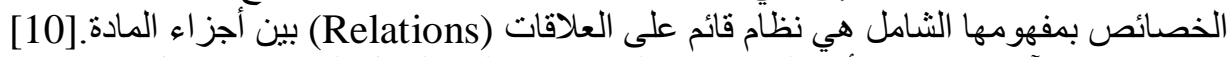

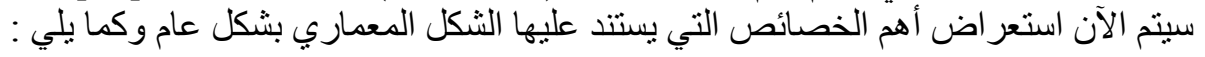

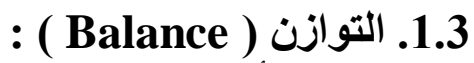

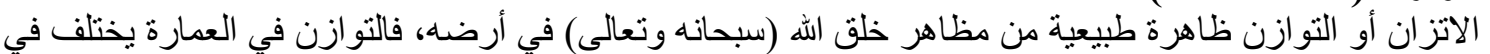

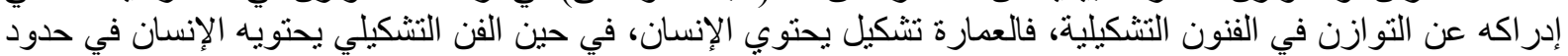

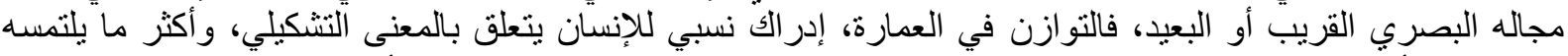

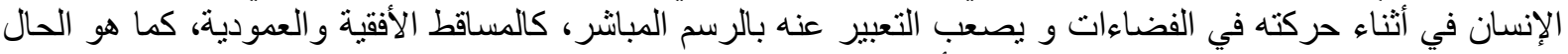

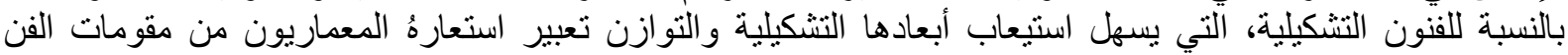

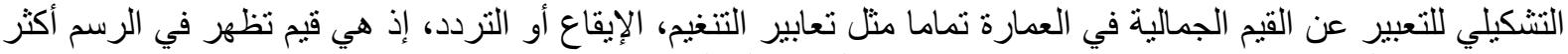

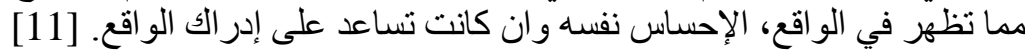

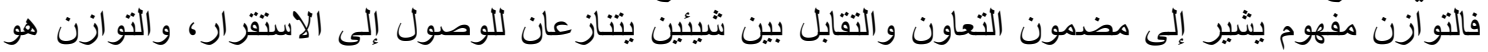

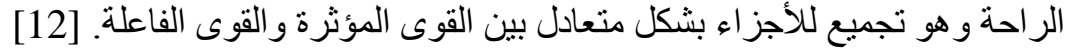

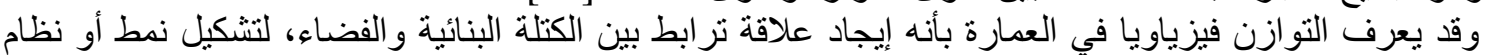

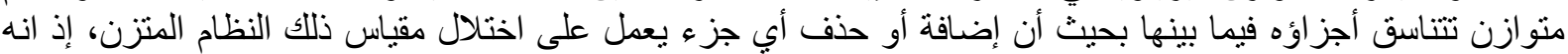

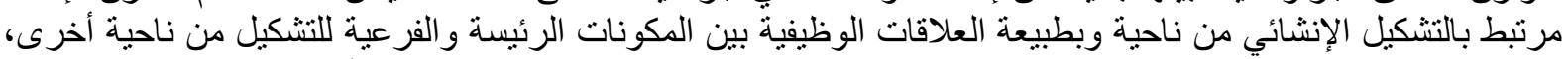

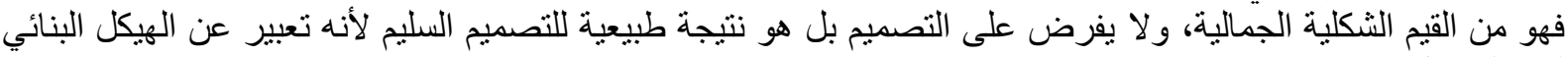

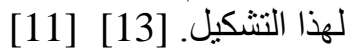

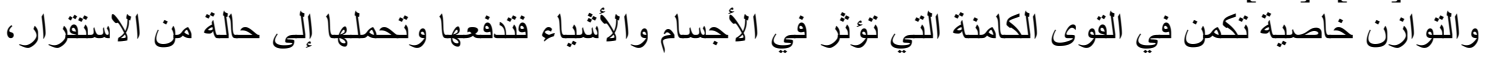

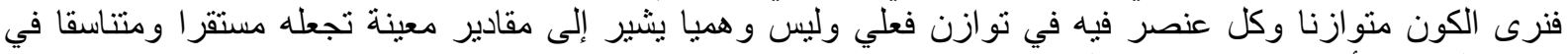

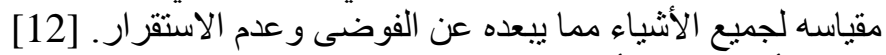

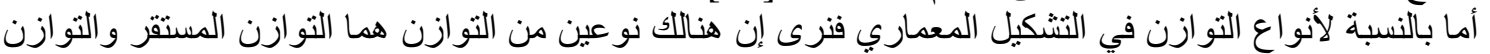

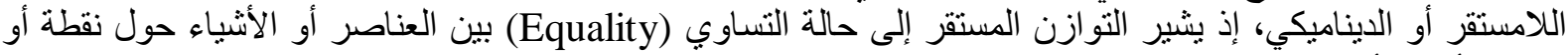
محور أفقية أو عمودية، في حين يشير اللامستقر إلى النقيض من ذللك، حيث نوزع التين العناصر بشكل غير التشاء

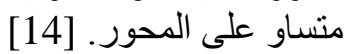

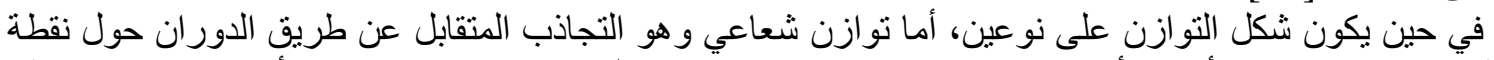

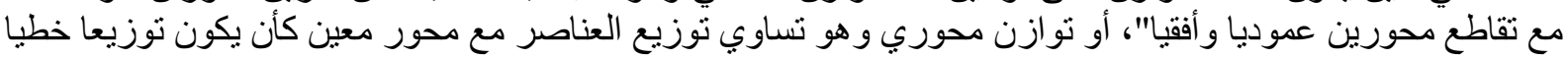

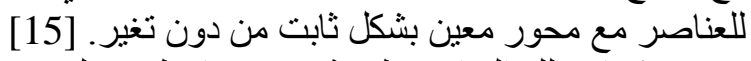

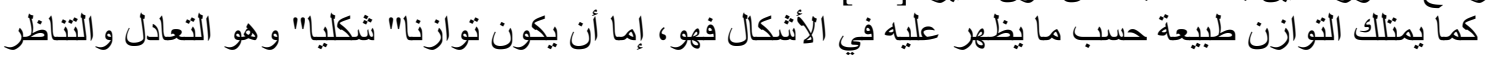

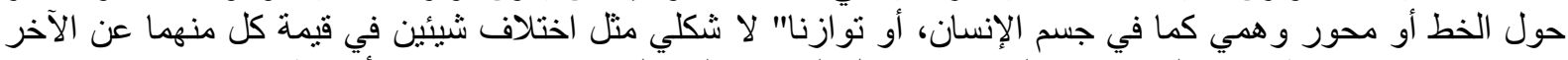

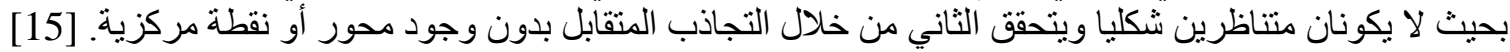

: 2.3. التكرار ( Repetition

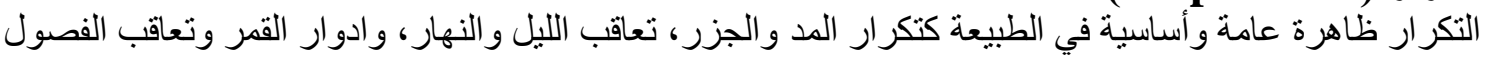

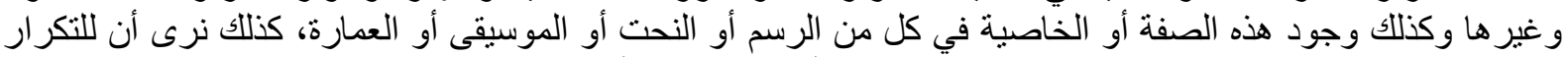

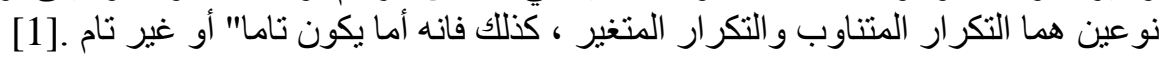

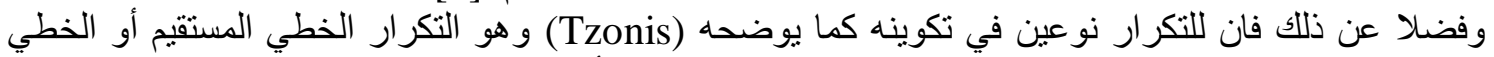

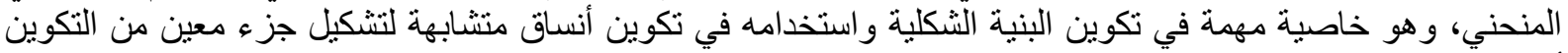

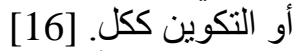
ونرى أن من الأمور التي يجب أن تؤخذ بنظر الاعتبار إن خاصية التكرار ودور ها في تشكيل التكوين الكلي في

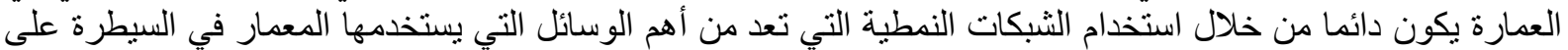

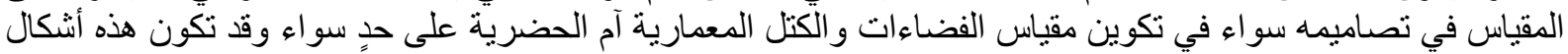

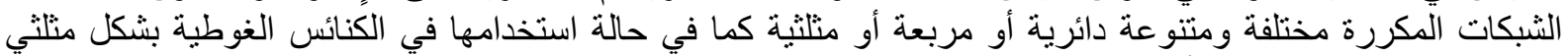

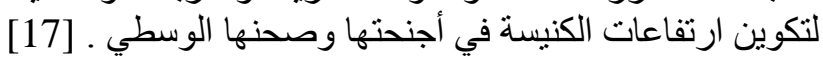


أما بالنسبة إلى كيفية تحقيق خاصية التكر ار في التكوين المعماري وإثر ها في البنية البصرية ، فقد ظهرت بأبأساليب

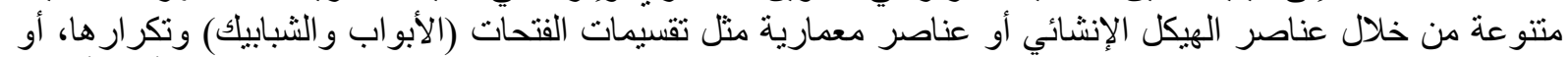

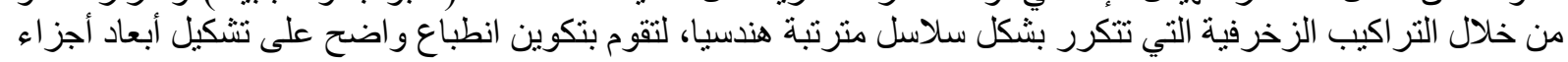

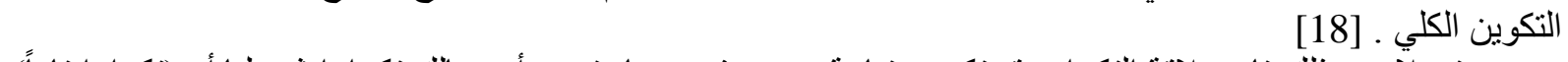

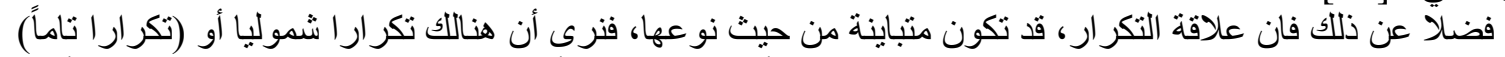

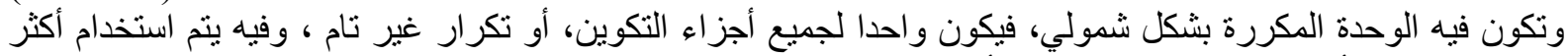

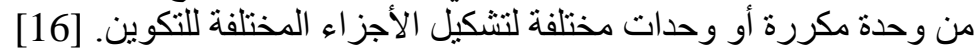

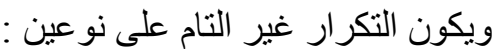

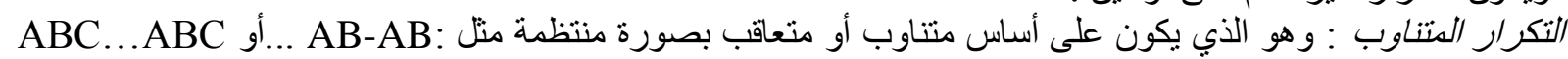

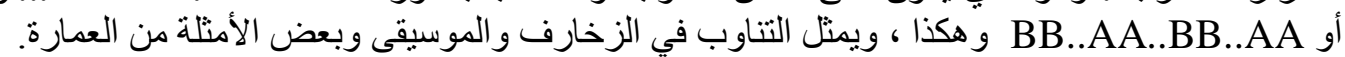

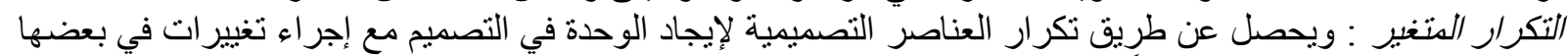

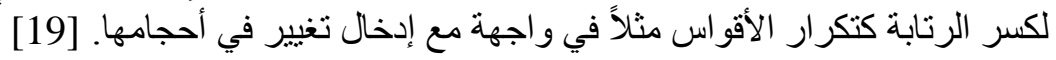

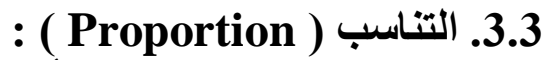
هي خاصية تمثل العلاقة بين أبعاد الفضاء الأفقية و العمودية فهي خاصية تشير إلى العلاقات الرياضية بين الأبعاد الحقيقية للشكل الفضائي ـ [3]

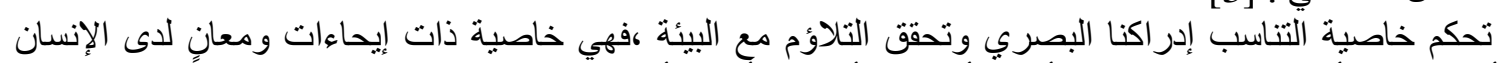

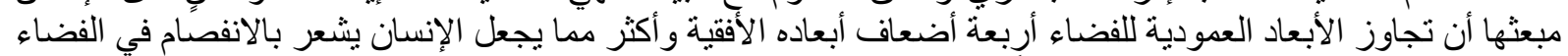

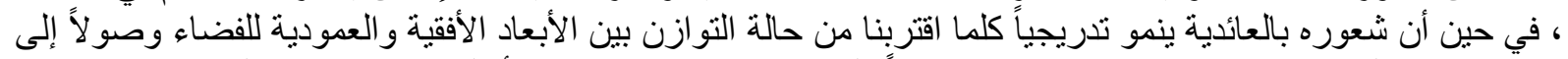

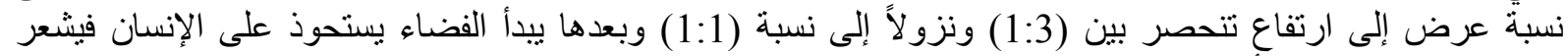

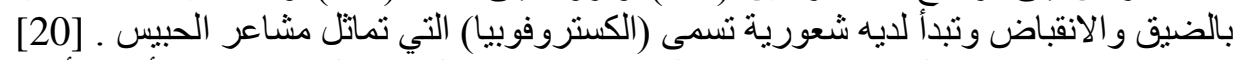

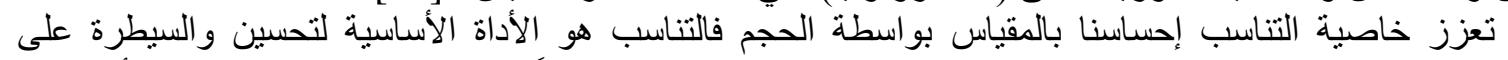

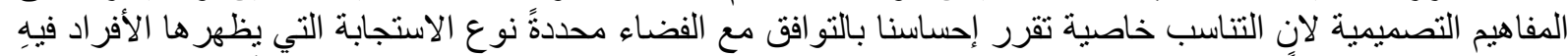

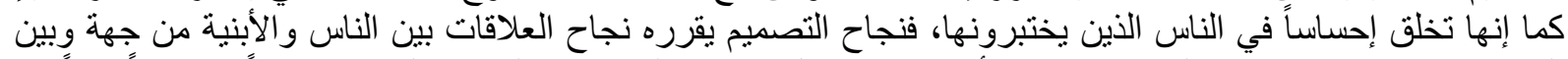

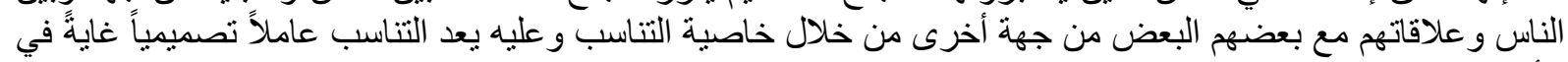

[21] الأهمية

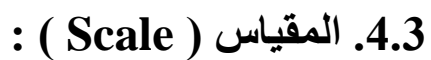

خاصية تنظم العلاقة بين حجم الفضاء المعاء المادي أو شكله مع حجم آخر (فضاء آخر أو الإنسان المحتوى فيه) ،لان المان

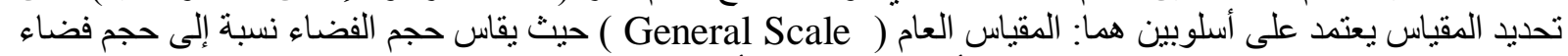

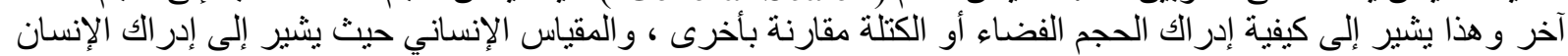

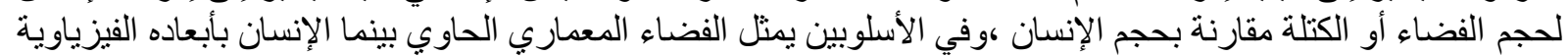

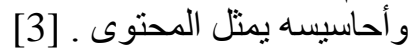

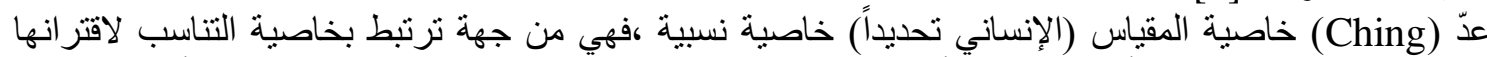

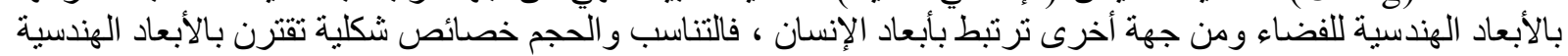

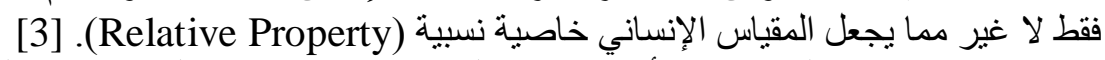

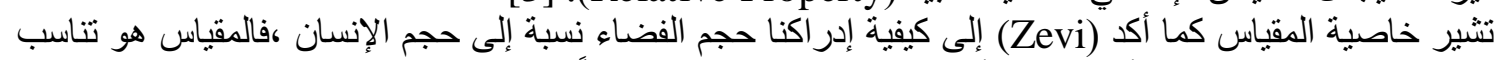

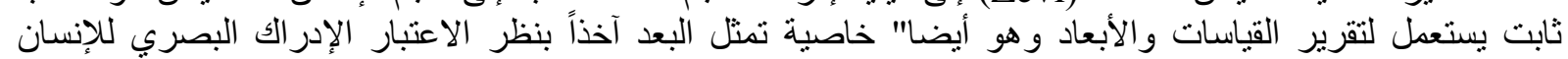

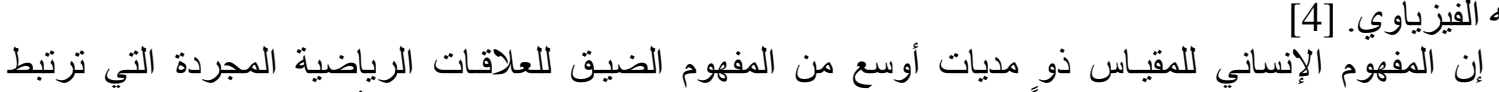

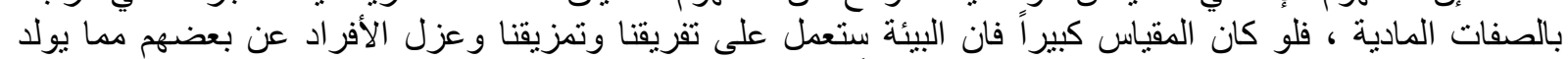

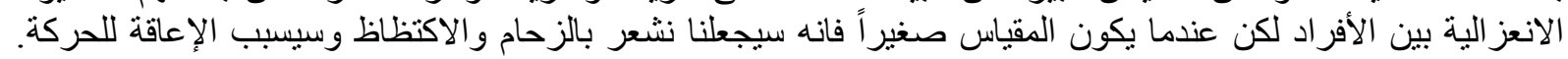

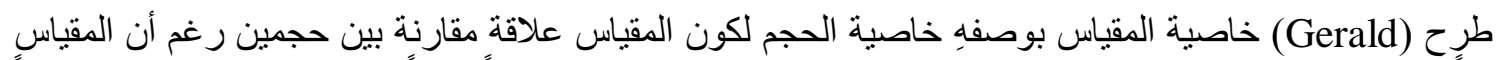

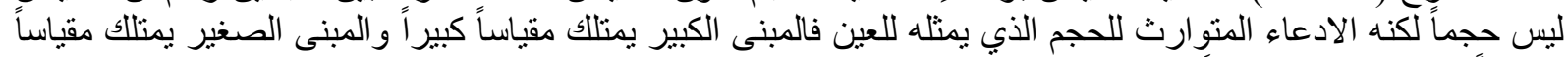

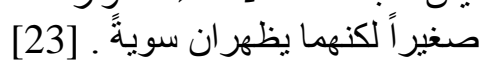


فالمقياس قد لا يعتمد على الحجم بشكل كلي رغم كونه مؤثراً مهماً إلا أن المعاني التي يثير ها أو التي يسقطها

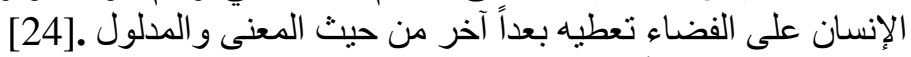

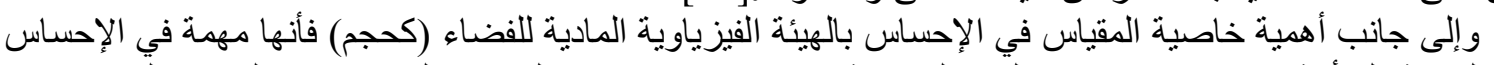

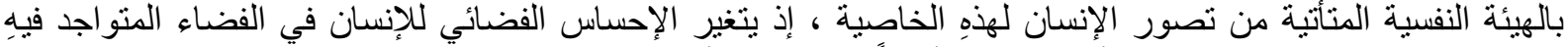

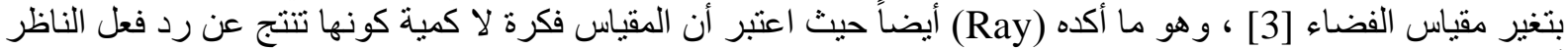

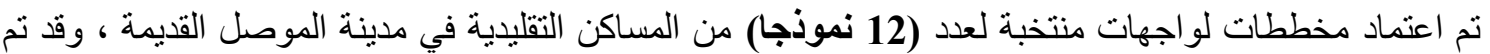

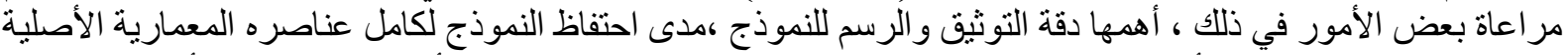

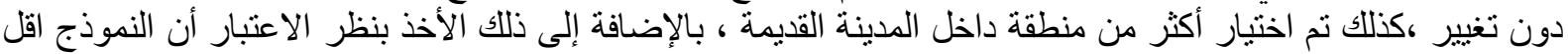

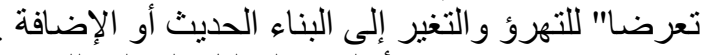
وقد تم استخدام أسلوب التحليل الثكلي للنماذج المعمارية المختارة قيد الدراسة، إضافة إلى استمارة وقد تضمنت

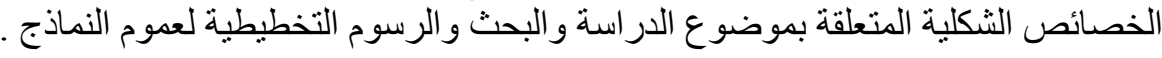

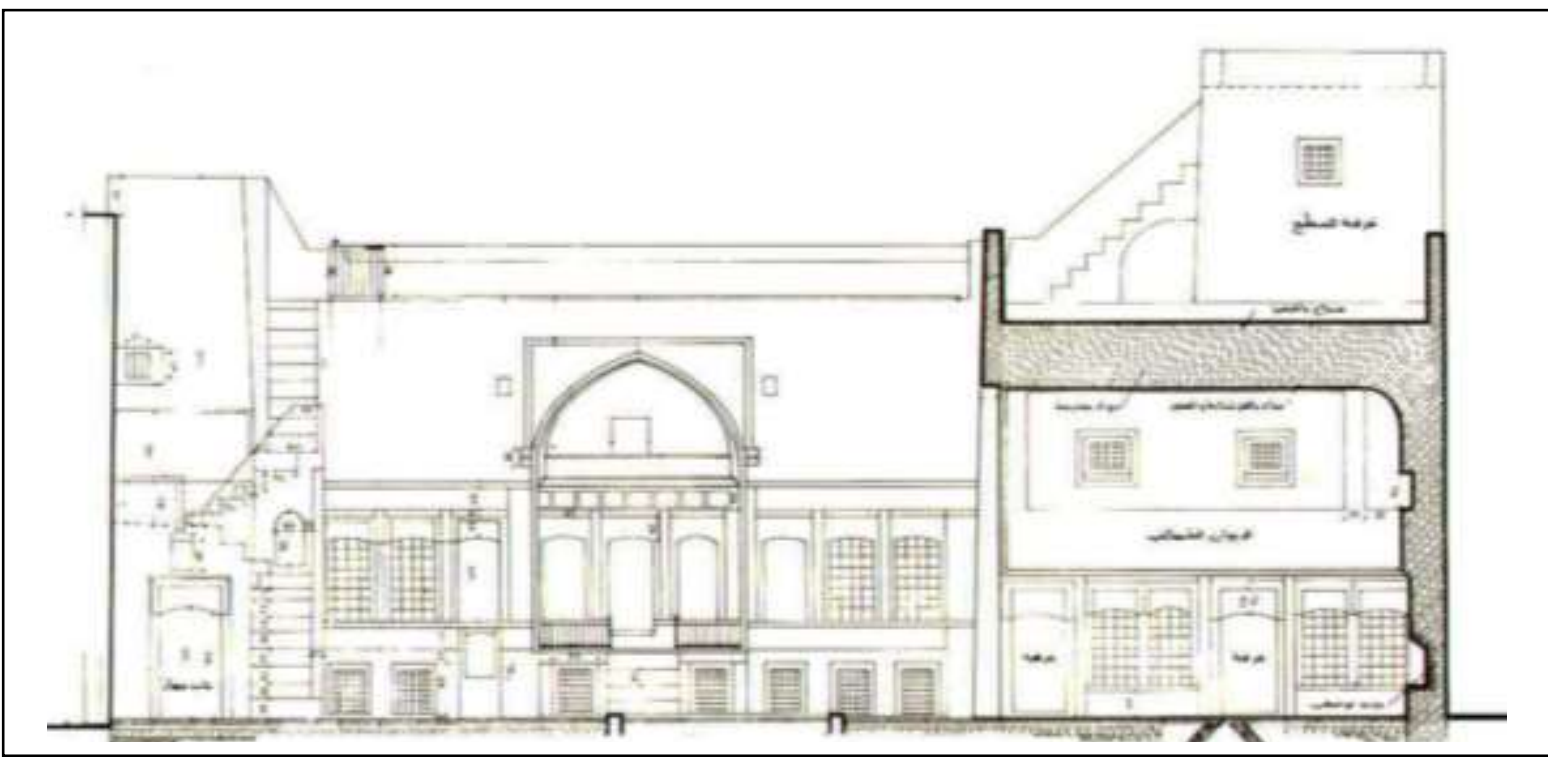

نموذج -1- ( بيت عبدوني ) الموقع : محلة المياسة (الموصل القديمة)

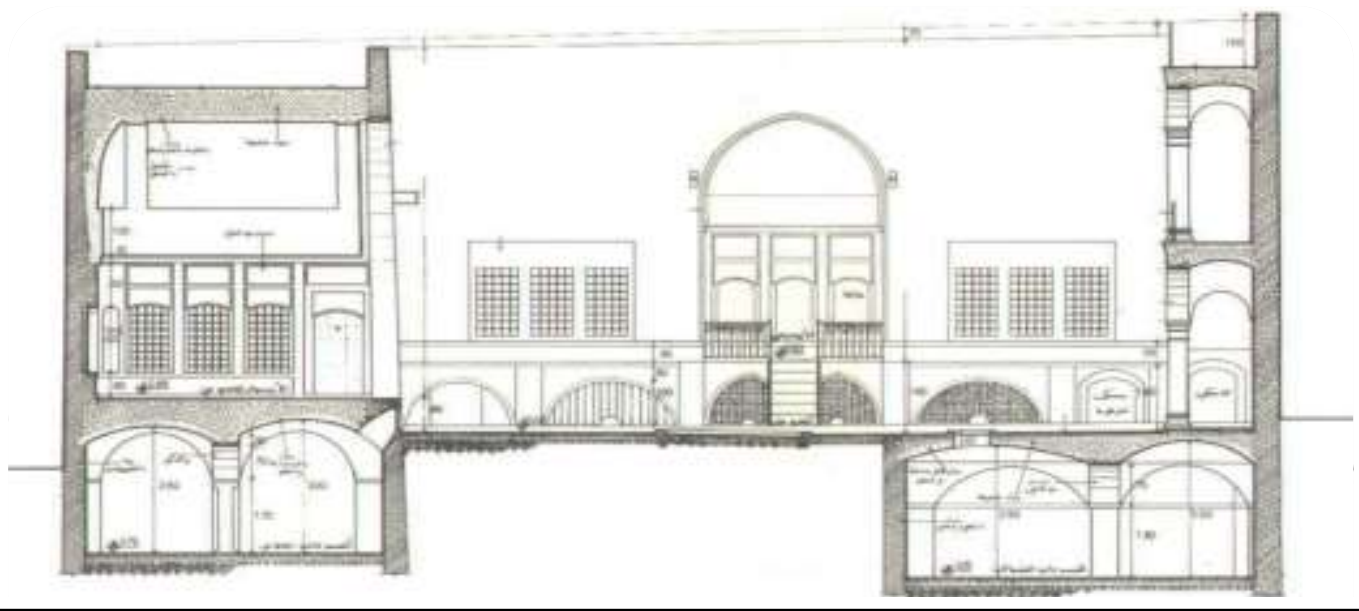

نموذج -2- ( بيت زيادة ) الموقع : محلة باب البيض الغربي (الموصل القديمة) 
العاني: خصائص الثكل المعماري للمسكن التقليدي الواجهات الداخلية للمسكن التقليدي في مدينة الموصل

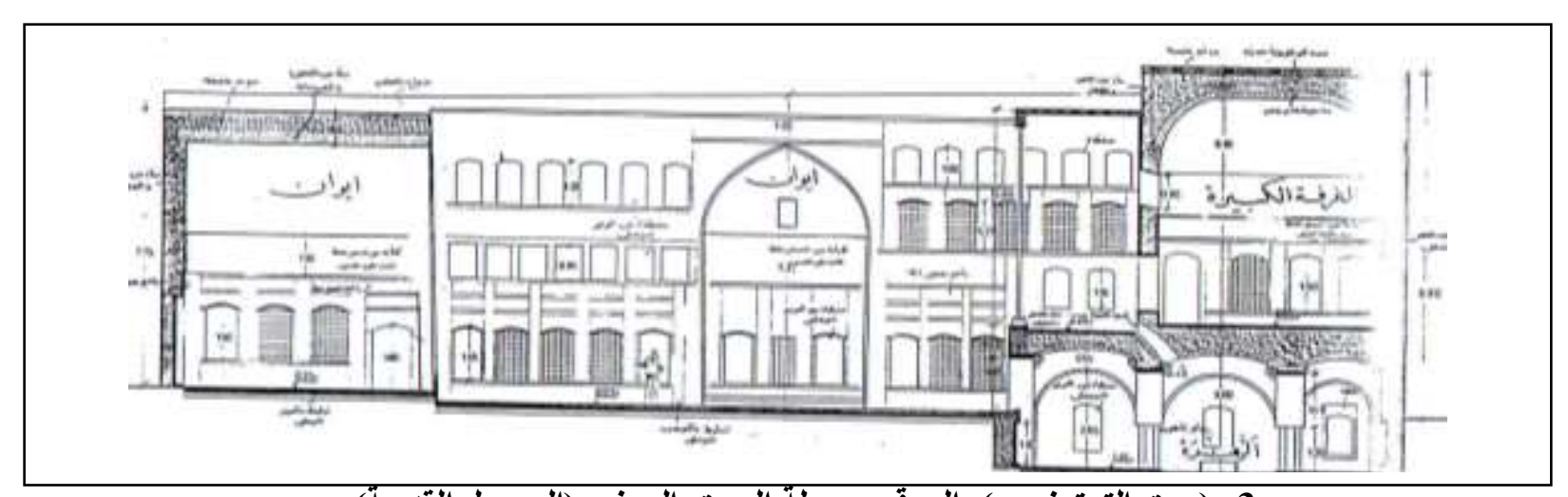

-3- ( بيت التوتونجي ) الموقع : محلة السوق الصغير (الموصل القديمة)

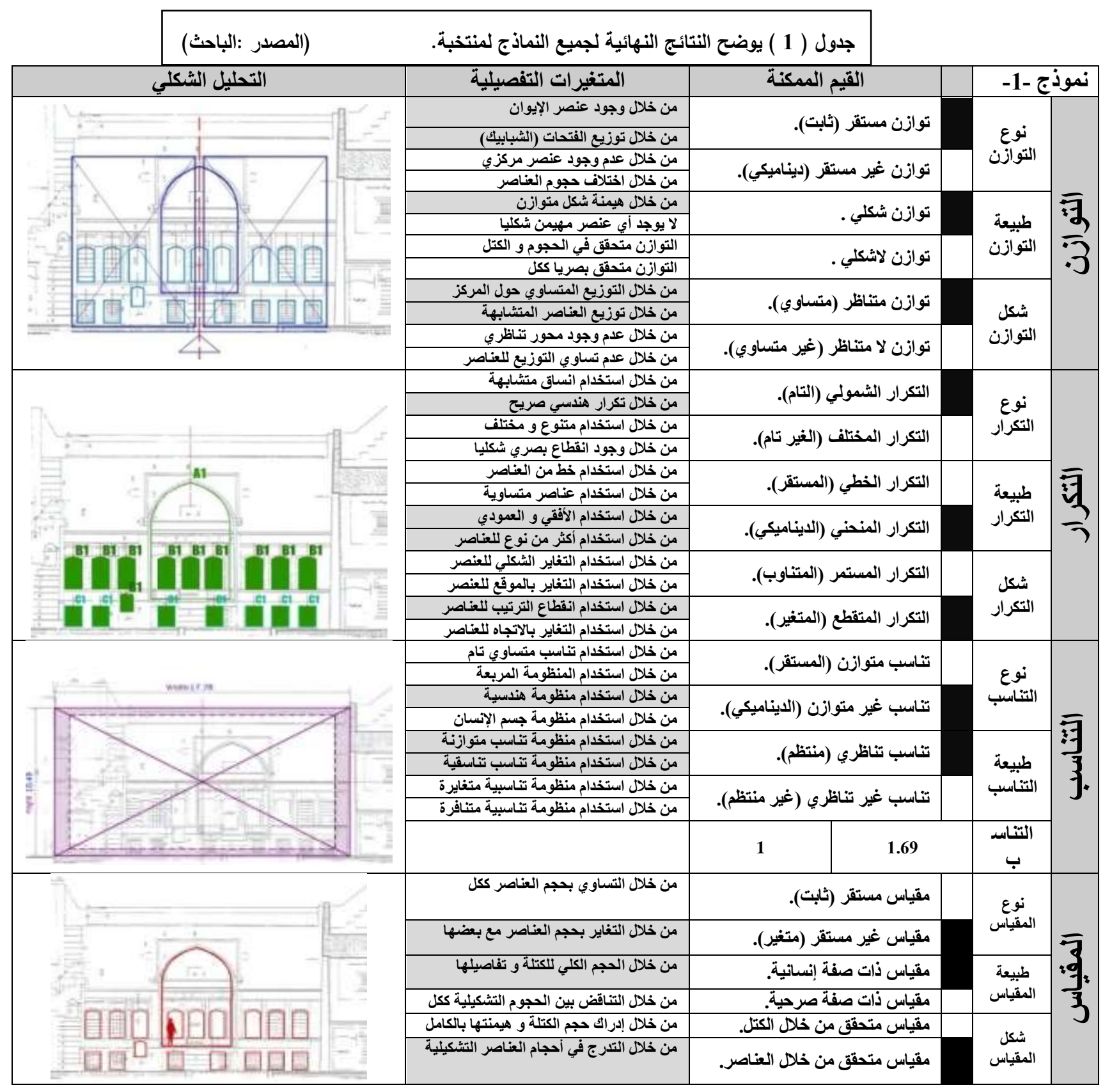




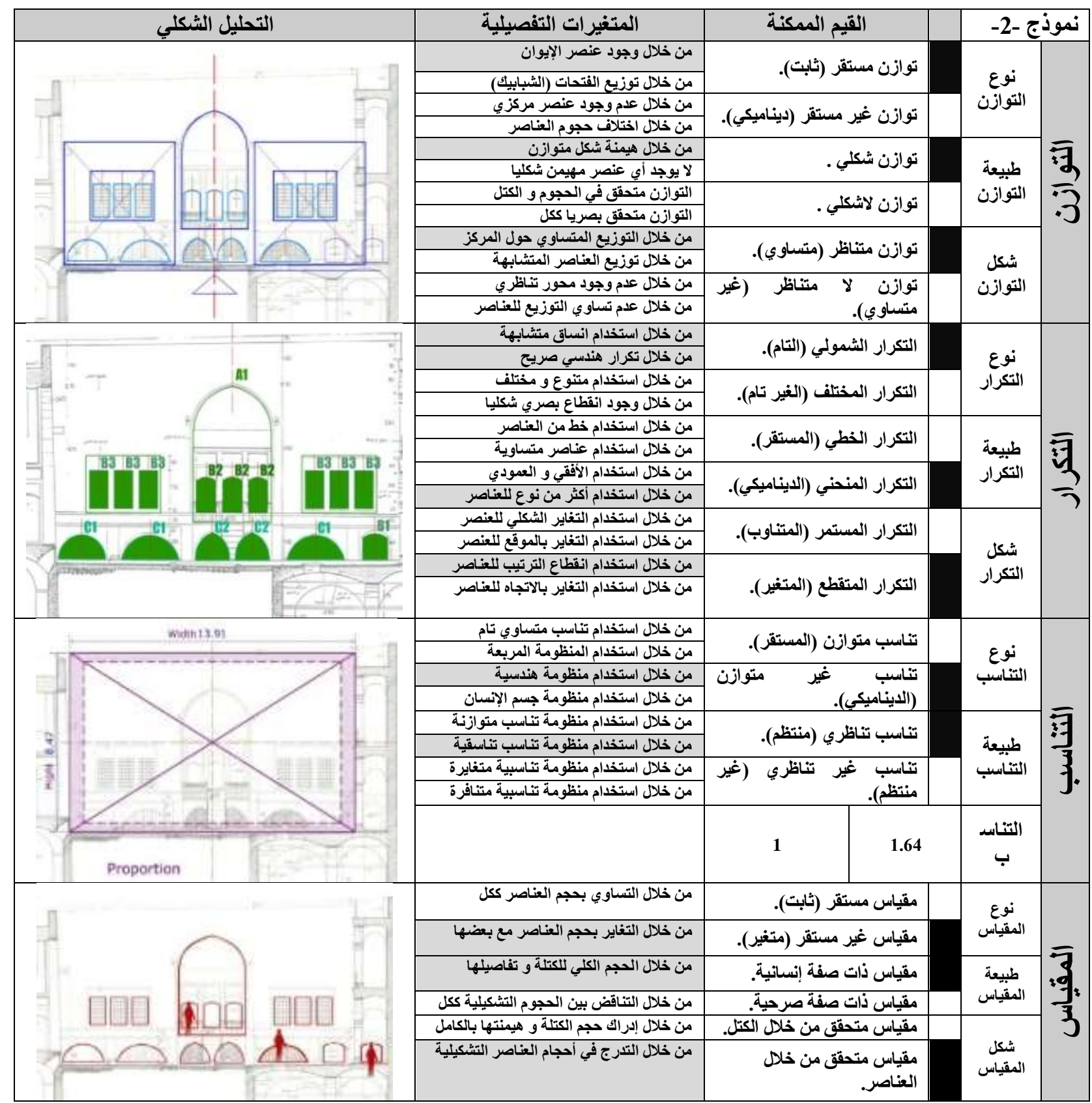


العاني: خصائص الثكل المعماري للمسكن التقليدي الواجهات الداخلية للمسكن التقليدي في مدينة الموصل

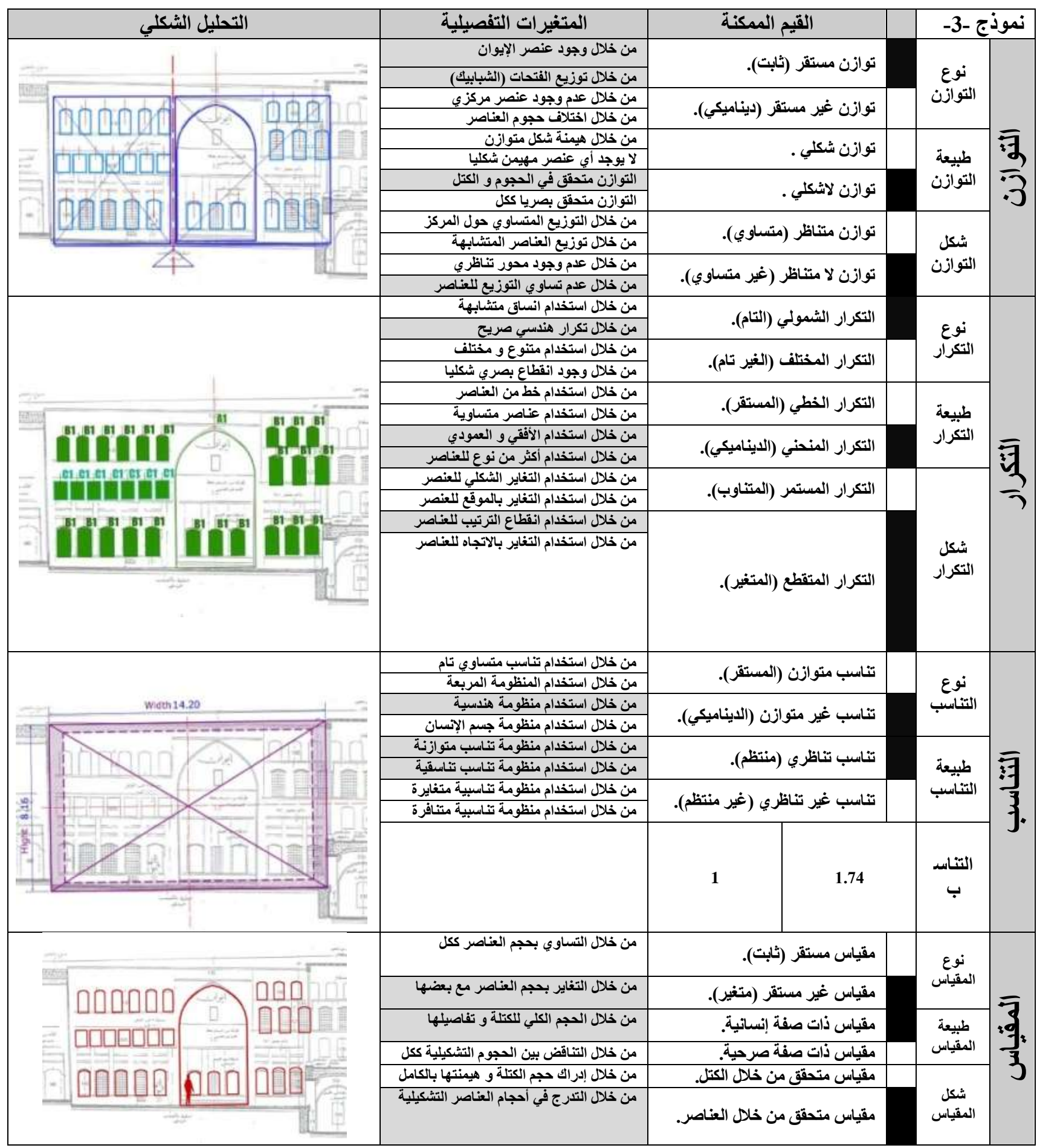


No. 2

March 2014

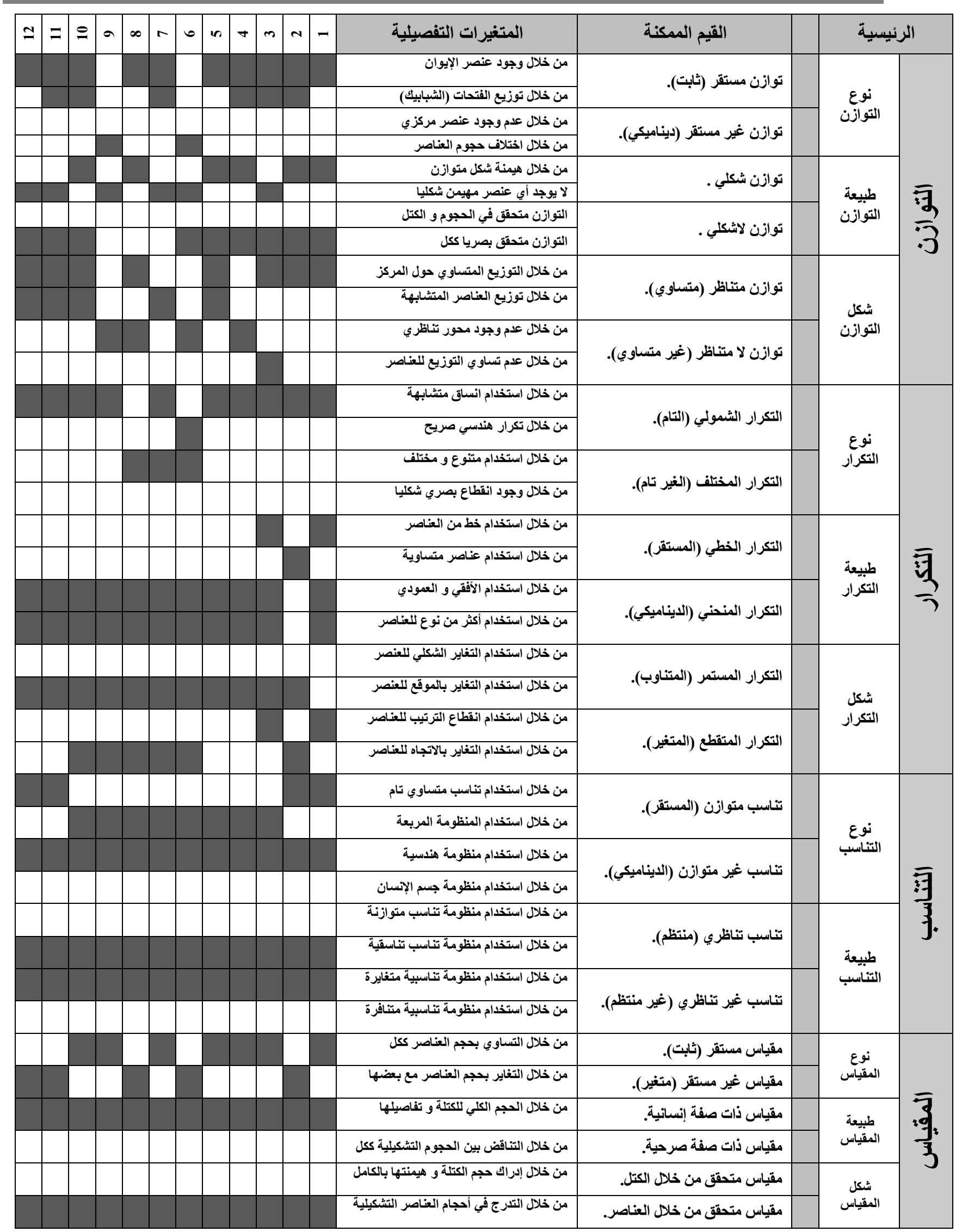




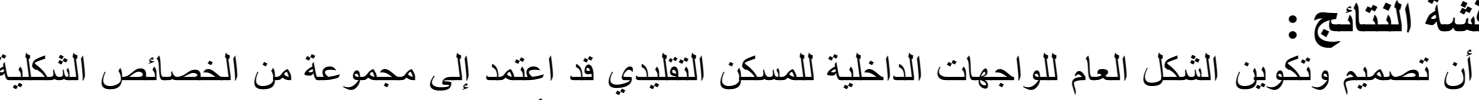

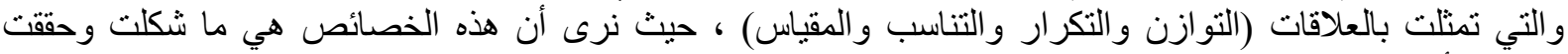

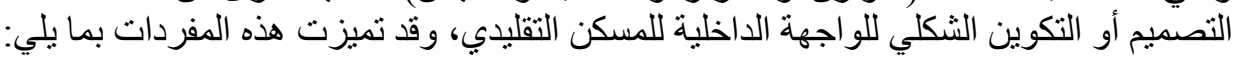

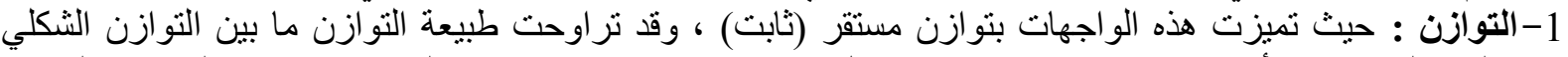

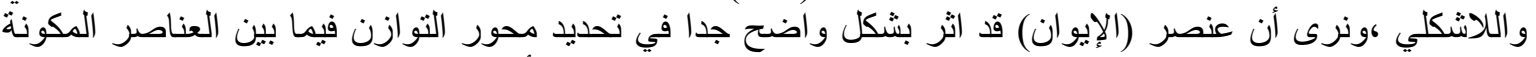

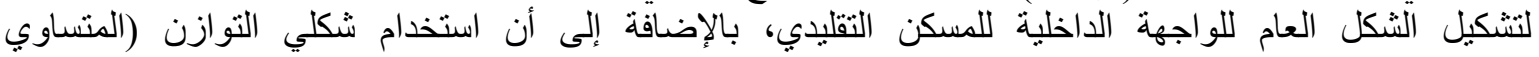

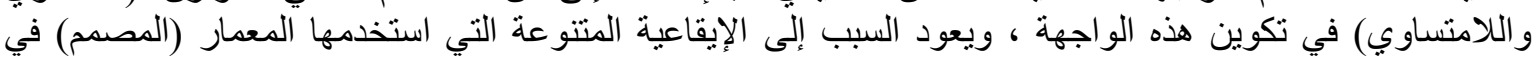

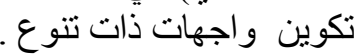

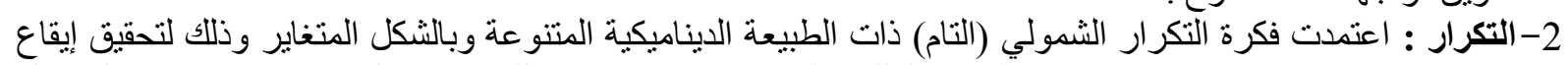

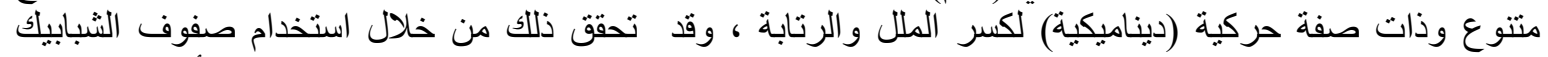

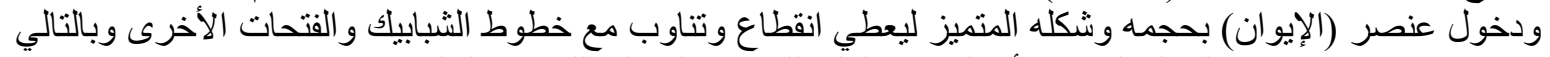

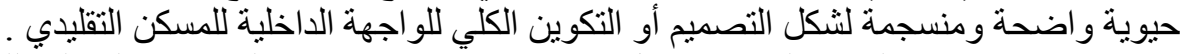

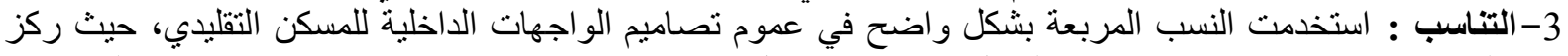

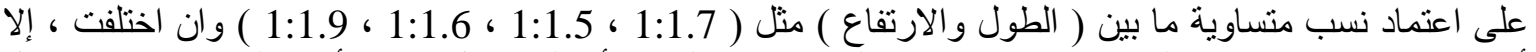

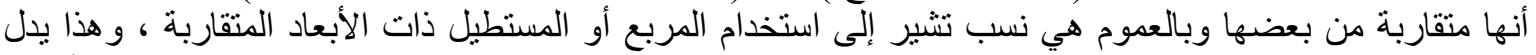

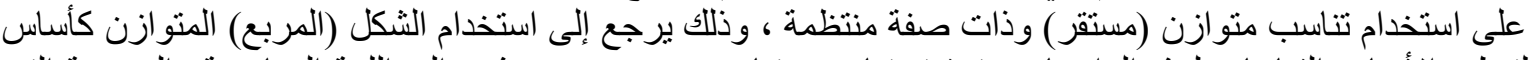

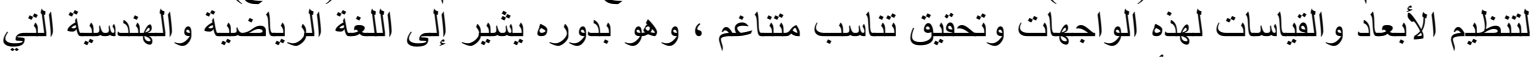

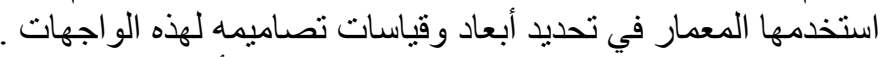

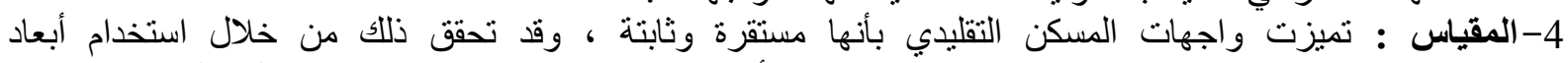

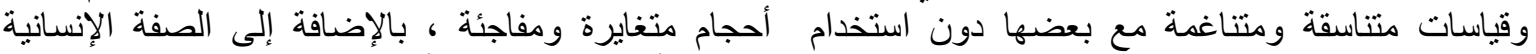

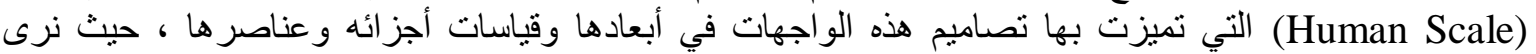

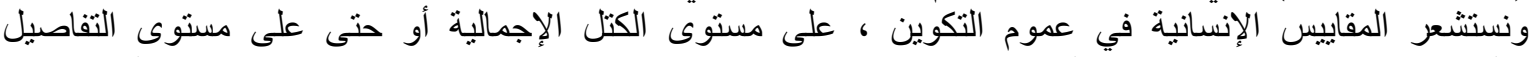

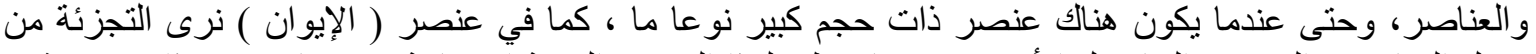

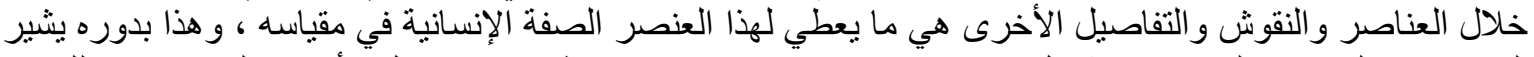

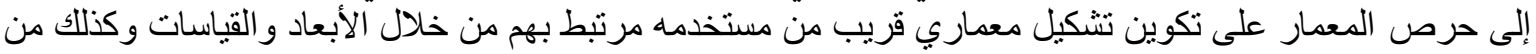
خلال الشعور بالر احة البصرية للمستخدم .

\section{1.6 الاستنتاجات النهائية : 1.

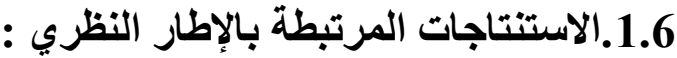

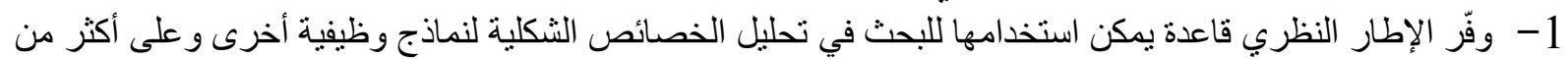

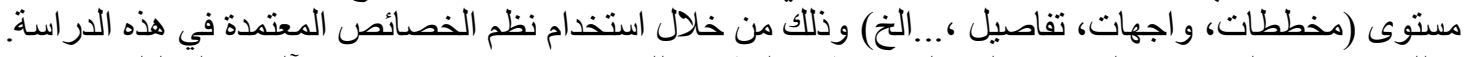

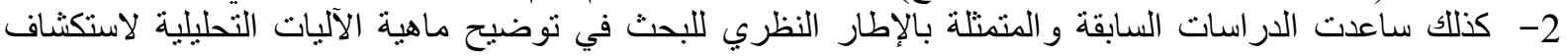

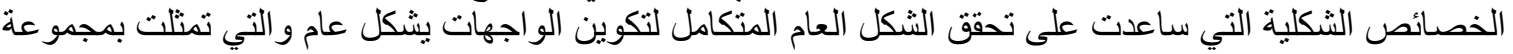

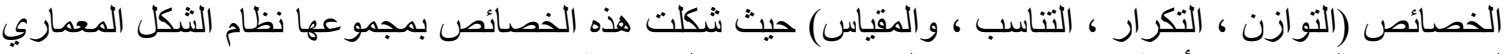

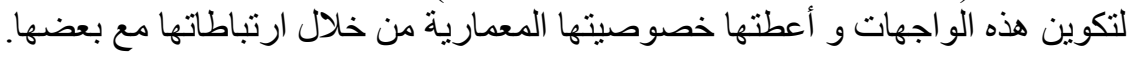

\section{6}

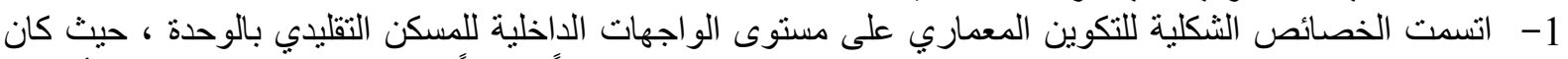

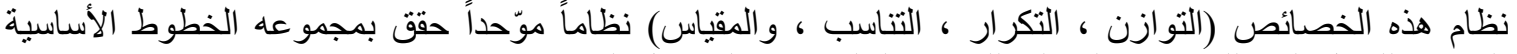

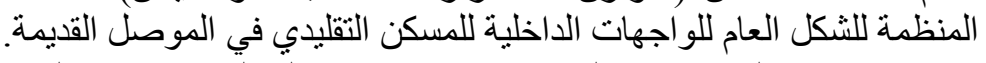

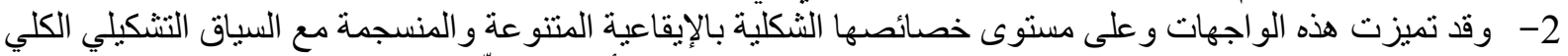

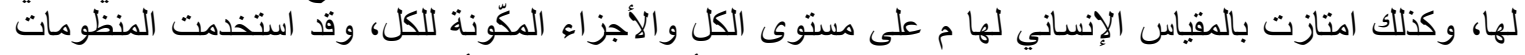

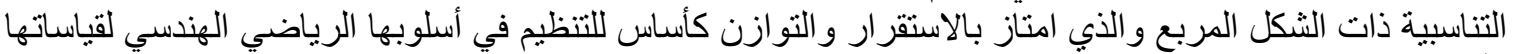
و أبعادها. 3- كان عنصر الإيوان بحجمه وشكله المميز، العنصر الأكثر أهية في تنظيم الواجهة الداخلية للمسكن التقليدي، حيث 
كان له التأثير (الإيوان) على تحقق الانقطاع و التناوب المتناغم لتكرار العناصر الأخرى في الواجهة، كذلك التهن اعتباره

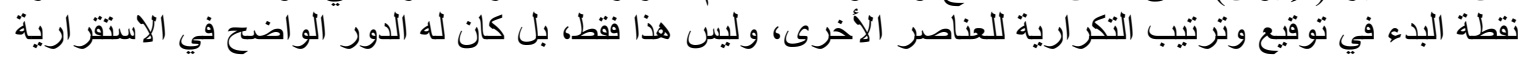

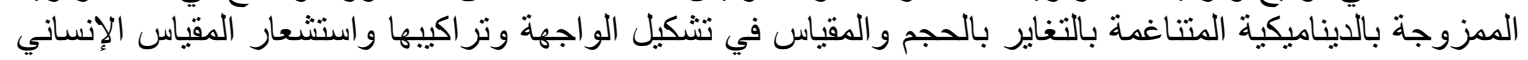
المميز لها.

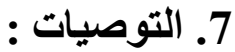

1- الاستفادة من ما توصل إليه البه البحث و على مستواه التحليلي كقاعدة يستند عليها المعماريون في محاو لاتهم التصميمية

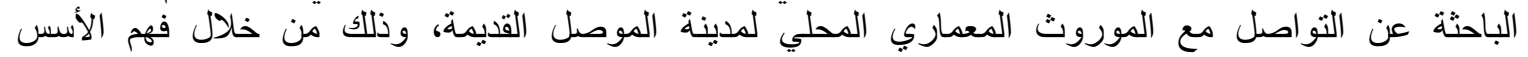
و الخصائص الثكلية و التكوينية لتلإك العمارة.

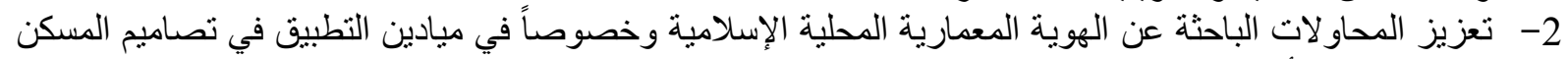

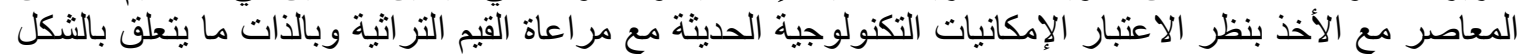

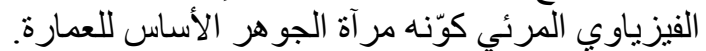

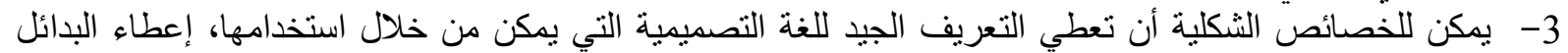

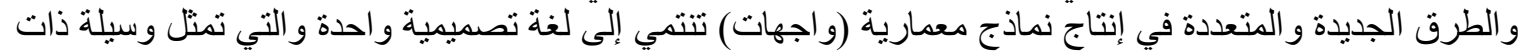

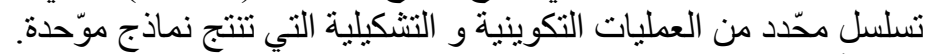

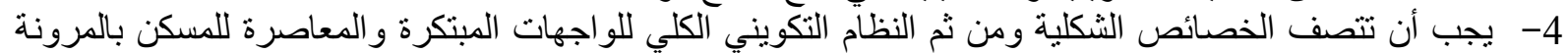

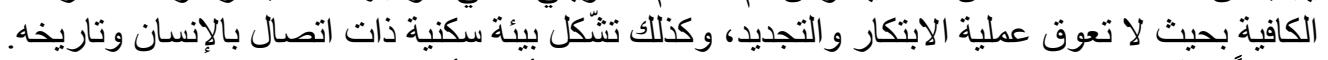

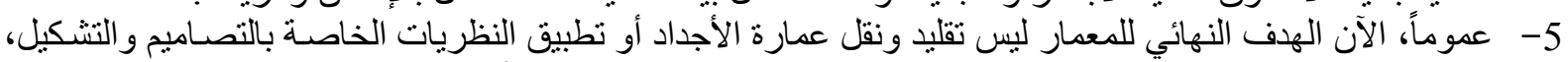

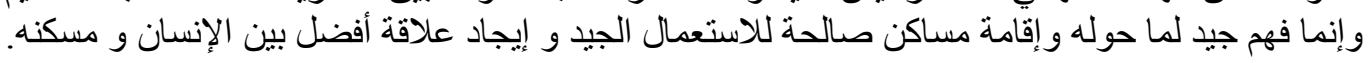

[1] Graves, Maitland, (The Art of Color and Design), the Maple press company, York, 1951. pp. $149-62-292$

[2] Mahgoub, Yasser (Form And Third Dimension) http:D.Yassermahgoub.htm-2004. p.5.

[3] Ching, F. D.K. (Architecture : Form, Space And Order) Van Nostrand Reihold Company-1996. pp. x-326-327-18-175.

[4] Zevi, Bruno (Architecture As Space) First Da Gapo press USA-1993. pp.13-196

[5] Crisman, Phoebe, (Form) University of Virginia School of Architecture http: WBGForm-Files.com-2004. pp.1-2-3

[6] Unwin, Simon (Analyzing Architecture) Routledge, New Fetter Lan, London, UK-1997. pp.105-34-107.

[7] Owen, S. P. (Physical Principles Underlying, Inorganic Form. In Aspects Of Form) lund Ham phries-1968. p.8.

[8] Thompson, D. Arcy (On Growth And Form) canbr, dueuniverity - Massachusetts, USA-1977. p.15.

[9] العبلي، كريم منعم (الثابت والمتغير في بنية الصورة للعمارة الإسلامية) رسالة ماجستير، غير منشورة، جامعة

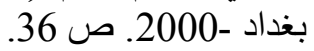

[10] Bonta, Juan (Notes On The Theory Of Meaning In The Design) John and Willey, New York, USA-1980. P. 28.

[11] إبراهيم، عبد البافي (بناء الفكر المعماري والعملية التصميمية) مركز الدراسات التخطيطية والمعمارية،

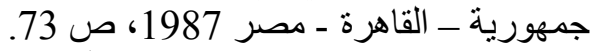

[12] العكيلي، قيس إبراهيم (سمات الجمالية في القرآن الكريم) رسالة دكنوراه، غير منشورة كلية الفنون الجميلة، جامعة بغداد-1998، ص ص العيل 167

[13] Trancik, R. (Finding Lost Space) printed in the USA-1986. p.106.

[14] Isaac, Arg (Approach to Architectural Design) friba Aibo Butterworth and Co., publisher, Ltd.,-1971. p.22.

[15] Scott, Robert Gillam (Design Fundamentals) McGraw Hill Company Inc.-1975. 
العاني: خصائص الثكل المعماري للمسكن التقليدي الواجهات الداخلية للمسكن التقليدي في مدينة الموصل

pp.45-46

[16] Tzonis, Alexander, and Lefaire (Classical Architecture-The Poetics Of Order) MIT press, England-1984.

[17] Licklider, Heath (Architectural Scale) the Architectural press, London, UK-1965. p. 119.

[18] Salingaros, Nikos (Hierarchical Cooperation In Architecture, And The Mathematical Necessity For Ornament) Journal of Architectural and Planning Research, Volume (17)-2000. p. 7.

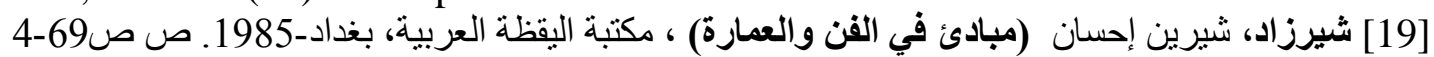

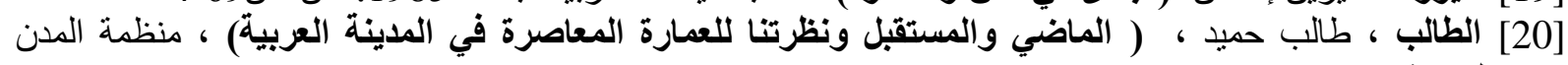

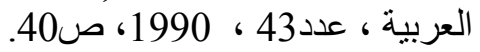

[21] Rubensten, M.Harvey, 1969, (a Gide to site and environmental planning), John Wiley and sons, INC, USA, p. 70.

[22] Eckbo, Garrett (The Landscape We See) McGrow Hill Book Company, USA-1969, p. 204.

[23] Cullen, Gordon (Town Scape) The Architectural press, London, England-1971. p. 79.

[24] شراد، حسين علي (المقياس الإنساني في تثكيل النسيج الحضري)، رسالة ماجستير، جامعة بغداد، مركز التخطيط

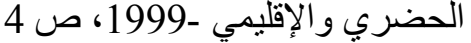

[25] المالكي، قبيلة فارس (الهندسة والرياضيات في العمارة)، دار الصفاء للنشر والتوزيع، عمان ـ الأردن - 2002،

ص97.

تم اجراء البحث فى كلية ألهندسة = جامعة ألموصل 